\title{
Zimography is an effective method for detection of matrix metalloproteinase 2 (MMP-2) activity in cultured human fibroblasts ${ }^{1}$
}

\author{
Rodolfo Assis Lisboa', Marcus Vinícius Andrade'II, José Renan Cunha-Melo ${ }^{\text {II }}$
}

${ }^{\mathrm{I}} \mathrm{PhD}$, Department of Pathology, School of Medicine, UFMG, Belo Horizonte-MG, Brazil, Acquisition, analysis and interpretation of data, statistical analysis and manuscript writing.

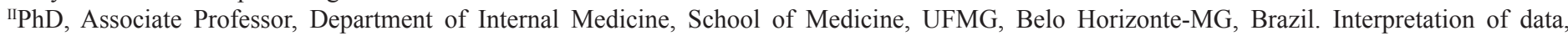
manuscript writing, critical revision, final approval of the version to be published.

IIIPhD, Full Professor, Department of Surgery, School of Medicine, UFMG, Belo Horizonte-MG, Brazil. Substantive scientific and intellectual contributions to the study, responsible for conception and design, interpretation of data, manuscript writing, critical revision, final approval of the version to be published.

\begin{abstract}
PURPOSE: To describe a method to characterize the gelatinase activity of cultured human periodontal fibroblasts stimulated with Pam $_{3}$ Cys and E. coli LPS, ligands of TLR2 and TLR4 respectively, and by centrifugation of the cultures, simulating an orthodontic force.

METHODS: To study MMP-2 activity, primary cultures of human periodontal fibroblasts were stimulated with the addition of TLRs 2 and 4 ligands and the application of mechanical force by centrifugation at $141 \mathrm{x} g$ for $30 \mathrm{~min}$. Supernatant media was collected 24 hours later to perform protein quantification and zymography.

RESULTS: MMP-2 activity suffered an increase in cultures co-stimulated with TLRs 2 and 4 ligands alone or with the presence of mechanical force application compared to basal levels.

CONCLUSION: Zymography, one of the several methods to study MMPs activities, is a simple, qualitative and efficient method based on electrophoresis of bis-acrylamide gels copolymerized with a protein substrate.
\end{abstract}

Key words: Zymography. Matrix Metalloproteinase 2. Fibroblasts. Periodontal Ligament. Toll-Like Receptors. 


\section{Introduction}

Metalloproteinases (MMP) are $\mathrm{Zn}^{2+}$ dependent endopeptidases responsible for the degradation of extracellular matrix on physiological and pathological conditions such as inflammation, neoplasms, wound healing, angiogenesis and matrix remodeling. Collectively, they are capable of degrading all kinds of extracellular matrix proteins and also process a number of bioactive molecules ${ }^{1}$. These enzymes are produced and released from cells as a latent form (Pro-MMP) and are activated by the removal of the $\mathrm{NH}_{2}$-terminal pro-peptide of approximately 10 $\mathrm{kDa}$. Their family are composed by 25 members divided on subfamilies: collagenases, gelatinases, matrilisyns, stromelisyns and membrane type $\mathrm{MMPs}^{2,3}$. The gelatinase sub-family is composed by gelatinase A (MMP-2) and gelatinase B (MMP-9) both capable of metabolizing native and denatured collagen, gelatin, elastin, laminin, fibronectin and the basement membrane ${ }^{1,2}$. Stromelysin (MMP-3) and matrilysin (MMP-7) also demonstrate broader substrate specificity like proteoglycans, gelatins, elastin, and glycoproteins ${ }^{4}$.

Several methods have been reported on literature to study the expressions and activities of MMPs, as an example: ELISA, Western Blotting, Immunohistochemistry, fluorometric oligopeptide substrates, radiolabeled collagen and zymography ${ }^{1-5}$.

Zymography is a simple and sensitive qualitative method based on the electrophoresis of SDS-PAGE gels copolymerized with a protein substrate. Gelatin is used as a protein substrate to evaluate the proteolytic activity of MMP-2 and MMP-9, casein for MMP-3, MMP-7 and MMP-10, and collagen for MMP-1 ${ }^{6,7}$. In a complex mixture as conditioned cultured cells media, biological fluids, or purified preparations, the zymography allows the identification of MMPs in their active and latent forms, based on molecular weight ${ }^{4-6,8}$.

Toll-like receptors (TLRs) are a family of patternrecognition receptors responsible for triggering inflammatory responses to microbial invasion. They recognize and distinguish the pathogen-associated molecular patterns (PAMPs), which are highly conserved structures of microorganisms ${ }^{9}$. TLRs can initiate the intracellular signaling cascade leading to inflammatory and immune gene transcriptions like cytokines and matrix metalloproteinases (MMPs) ${ }^{10}$.

The aim of the study is to demonstrate that the zymography can be used to evaluate the gelatinase activity of cultured human periodontal fibroblasts. The cells were stimulated with $\mathrm{Pam}_{3} \mathrm{Cys}$ and E. coli LPS, ligands of TLR2 and TLR4 respectively, or by centrifugation of the cultures at $141 \mathrm{x} g$ for $30 \mathrm{~min}$, a simulation of orthodontic force, as previously described ${ }^{1}$.

\section{Methods}

\section{Fibroblast cultures}

Human periodontal fibroblasts were obtained from primary cultures of periodontal ligament explants. Healthy donors with indication for exodontia of enclosed third molars were selected at the Dental School of the Minas Gerais Federal University (UFMG), Brazil and invited to participate in the study, donating their extracted teeth. The study was approved by the Ethical Committee for Research, UFMG, Brazil (COEP-UFMG, license no. ETIC 0078.0.203.000-11 - 14/06/2011) and informed consent were obtained from all patients.

Teeth which had been sectioned during the surgery and those who hadn't more than half of the root formed were discarded due to difficulty to immobilize the crown for tissue extraction and lack of periodontal tissue.

Extracted teeth were immersed in DMEM culture medium (Gibco, Grand Island, NY), with 1\% antibiotic-antimycotic (Gibco) and 10\% FCS (Sigma, St. Louis, MO) and transported to the Lineu Freire-Maia Laboratory at the Medical School, UFMG, Brazil. Teeth were rinsed with $70 \%$ ethanol solution followed by washing out with $0.9 \% \mathrm{NaCl}$. Periodontal ligament were removed from the middle third roots and fragmented. The explants were transferred to a $25 \mathrm{~cm}^{2}$ culture flask containing the same culture medium used on transportation. Cultures were incubated at $37^{\circ} \mathrm{C}$ and $5 \% \mathrm{CO}_{2}$ until confluence in which the medium was changed every three days. Fibroblasts were trypsinized ( $0.25 \%$ trypsin; trypsin-EDTA, Gibco) and transferred to a $75 \mathrm{~cm}^{2}$ culture flask. On the third passage, the cells were seeded on 48 well plates for treatment.

\section{Culture stimulation}

Cells were washed out with $0.9 \%$ saline and a serum-free DMEM medium was added prior to stimulation. Experimental and control groups were planned. On the experimental groups, cultures were stimulated with $1 \mu \mathrm{g} / \mathrm{mL}$ of Pam $_{3}$ Cys or E. coli LPS or by centrifugation at $141 \mathrm{x} g$ for $30 \mathrm{~min}$ or combination of the stimuli as follows: Control group (CT), Centrifugation group (CTc), TLR4 ligand (LPS), TLR2 ligand (P3C), TLR4 + centrifugation (LPSc), TLR2 + centrifugation (P3Cc), TLR2 + TLR4 (PL), TLR2 + TLR4 + centrifugation (PLc). The cells were stimulated for 24 hours in a $5 \% \mathrm{CO}_{2}$ incubator and supernatant collected. Samples were stored at $-20^{\circ} \mathrm{C}$ until the gelatin zymography assay. 


\section{Cell viability assay}

After stimulation, cell viability was tested under optical microscopy after the addition of $0.4 \%$ Trypan blue (BioWhittaker, Walkersville, MD, cat. 17-942E). The numbers of stained and non stained cells were determined to avoid bias caused by stimulationinduced cell death.

\section{Protein assay}

A BCA spectrophotometric (490-nm wavelength). Protein Assay Kit (Pierce, Rockford, IL), was used for total protein quantification of culture media samples

\section{Zymogram}

Gelatin zymograms were performed as follows: $10.5 \%$ SDS-polyacrylamide separating gels with $2 \mathrm{mg} / \mathrm{mL}$ of gelatin (30\% bis-acrylamide, $1.5 \mathrm{M}$ tris-HCL $\mathrm{pH} 8.8,10 \%$ ammonium persulfate, $0.04 \%$ TEMED, $10 \%$ SDS and distilled water to reach final volume) and 5\% SDS-polyacrylamide staking gels (30\% bisacrylamide, $1 \mathrm{M}$ tris-HCL $\mathrm{pH} 6.8,10 \%$ ammonium persulfate, $0.1 \%$ TEMED, $10 \%$ SDS and distilled water to reach final volume) were prepared. Solutions were cast on Mini Protean (BioRad) with the addition of ammonium persulfate and TEMED to polymerize the gels (1 mm thickness). The gels were loaded with samples diluted in 1:1 non-reducing buffer $(12.5 \% 0.5 \mathrm{M}$ Tris- $\mathrm{HCl} \mathrm{pH}$ $6.8,10 \%$ glycerol, $4 \%$ SDS, and $0.05 \%$ bromophenol blue) and the electrophoresis was carried at $4{ }^{\circ} \mathrm{C}$ using a constant current of $35 \mathrm{~mA}$ at $90 \mathrm{~V}$ for approximately $5 \mathrm{~h}$. After disassembling the apparatus, gels were washed $2 \mathrm{X}$ in $2.5 \%$ triton-x 100 for 15 minutes, incubated on incubation buffer (Tris- $\mathrm{HCl} 50 \mathrm{mM}, \mathrm{CaCl} 2$ $10 \mathrm{mM}, \mathrm{NaCl} 50 \mathrm{mM}, \mathrm{pH} 7.6$ ) for 18 hours at $37^{\circ} \mathrm{C}$, stained by $0.1 \%$ Coomassie brilliant blue R-250 solution (with $40 \%$ methanol and $10 \%$ acetic acid) for $4 \mathrm{~h}$ under gentle shaking and destained $2 \mathrm{X}$ for 20 minutes with $25 \%$ ethanol and $8 \%$ acetic acid solution. Gels were scanned at $600 \mathrm{dpi}$ and analysed for densitometry at Kodak Molecular Imaging Software 4.0.5.

The gels were washed out with distilled water and scanned (Genius ColorPage-Vivid Pro II at 600dpi) for densitometry (Kodak Molecular Imaging software v.4.0.1).

\section{Results}

Cell viability assay showed no significant difference between groups (Kruskal Wallis, $\mathrm{p}>0.05$ ).

Non-stained bands were shown at a blue background gel revealing the gelatin digestion by MMPs at its respective molecular weight.
Sample derived from human periodontal fibroblast culture media collected 24 hours after stimulation revealed only activity for $72 \mathrm{kDa}$ MMP-2 on gelatin zymography. MMP-9 was not detected as depicted in Figure 1.
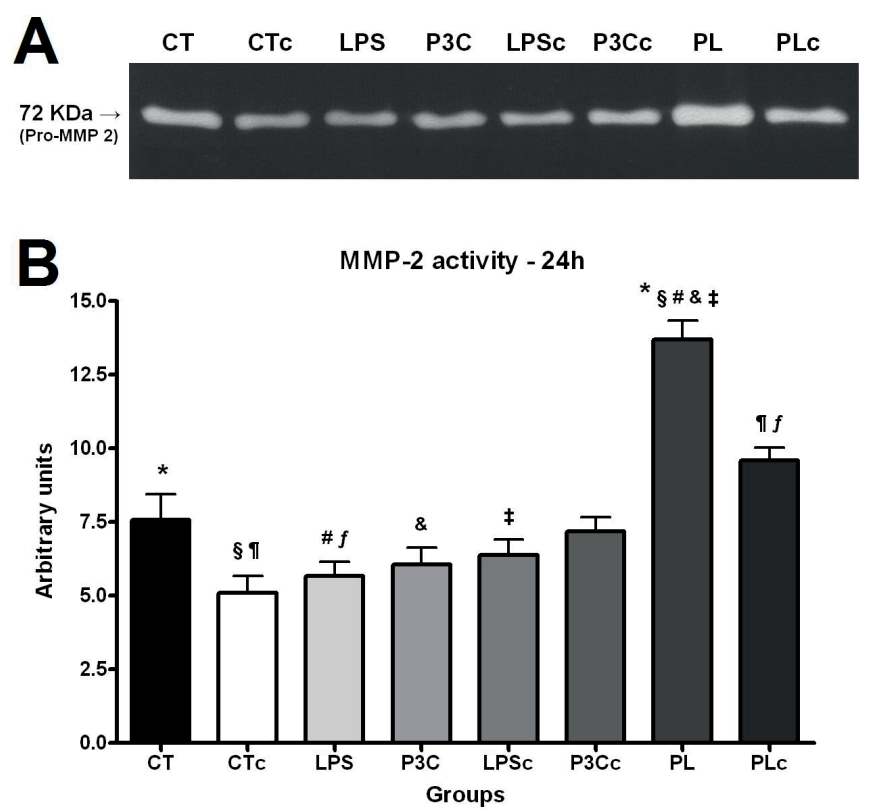

FIGURE 1 - A - Gelatin zymography showing the activity of $72 \mathrm{kDa}$ MMP-2 present in culture medium samples. CT (Control group), CTc (Centrifugation group), LPS (TLR4 ligand group), P3C (TLR2 ligand group), LPSc (TLR4 ligand + centrifugation), P3Cc (TLR2 ligand + centrifugation), PL (TLR4 ligand + TLR2 ligand), PLc (TLR4 ligand + TLR2 ligand + centrifugation). B - Densitometry showing different activities of $72 \mathrm{kDa}$ MMP 2 in medium samples showed in A. The $72 \mathrm{kDa}$ form of MMP-2 showed increase activity in group PL (* Dunn's posttest, $\mathrm{p}<0.05), \mathrm{CTc}$ (§ Dunn's post-test, $\mathrm{p}<0.001)$, LPS (\# Dunn's post-test, $\mathrm{p}<0.01$ ), P3C (\& Dunn's post-test, $\mathrm{p}<0.01$ ) and LPSc ( $\$$ Dunn's post-test, $\mathrm{p}<0.01)$. There was also an increase in PLc ( Dunn's post-test, $\mathrm{p}<0.001$ ) and LPS ( $f$ Dunn's post-test, $\mathrm{p}<0.01$ ).

The activity of $72 \mathrm{kDa}$ MMP-2 in culture medium of cells after stimulation with both LPS+Pam ${ }_{3}$ Cys (PL) showed an increase (Kruskal Wallis, $\mathrm{p}<0.0001$ ) when compared to control $(p<0.05)$, centrifugation group $(p<0.001)$, LPS $(p<0.001)$, P3C $(p<0.01)$ and LPS + centrifugation $(p<0.01)$, (Dunn's post-test).

In the groups treated by LPS + Pam3Cys + centrifugation (PLc), the activity of the $72 \mathrm{kDa}$ presented an increase when compared to cultures treated by centrifugation $(\mathrm{p}<0.001)$ or by LPS $(p<0.01)$ (Dunn's post-test).

\section{Discussion}

The method of tissue collection from healthy teeth (no association with dental caries and periodontal diseases) on a surgical environment for fibroblast culture allowed a low index of 
culture contamination.

Cell viability was determined to check if centrifugationinduced cell death might interfere with the results. A decrease of more than $20 \%$ on cell viability below control levels has been shown to interfere with the reliability of the data ${ }^{1,11}$. In our study, no significant difference was found on cell viability ratio between control and experimental groups.

MMP-2 was the only MMP showing activity by gelatin zymography with an observed effect on a $72 \mathrm{kDa}$ form. The $72 \mathrm{kDa}$ MMP-2 has gelatinolytic activity thanks to the disruption between the $\mathrm{Zn}^{2+}$ and the free thiol radical present in a cysteine conserved region of its prodomain ${ }^{12}$.

The centrifugation alone does not induce an increase in MMP2 activity. However, the simultaneous activation with toll-like receptors agonists, TLRs 2 and 4, induced a two times fold increase in MMP-2 activity when compared to basal levels. The data seem to indicate a potentiation of the isolated stimulation by either one of these ligands. In addition, cells treated by simultaneous addition of TLRs 2 and 4 followed by centrifugation, have shown MMP-2 activity twice as higher than isolated stimulation by centrifugation.

Zymogaphy is one of the most sensitive and reliable method to study the proteolitic activity of MMPs. This method is able to detect picograms of the enzyme and to distinguish active and latent form from different $\mathrm{MMPs}^{3,5,8,13}$ based on their molecular weight. Additional advantages of this method are its simplicity and low cost.

Even considering, during the electrophoresis, that gel conditions cause protein denaturation, the MMP-2 activity as demonstrated by gel destaining may be explained. The enzymes are separated under denaturing by sodium dodecyl sulfate (SDS) at non-reducing conditions. The removal of the SDS, usually by Triton X-100 and the incubation in the proper buffer, promotes protein renaturation and activity, allowing the visualization of bands after the staining and distaining procedures ${ }^{8}$.

The observed potentiation of both TLR2 and TLR4 ligands on MMP-2 activity seems to indicate that Toll-like Receptors may play a roll in the modulation of inflammatory responses in the periodontal ligament fibroblasts. These receptors are significantly more expressed on periodontal tissue during inflammation $^{14,15}$. In vitro, human periodontal fibroblasts showed increased expression of TLRs 2 and 4 after infection by Gram negative periodontal bacteria ${ }^{14}$. Also Porphyromonas gingivalis, a gram negative anaerobe bacteria, is associated with bone loss on periodontal disease is thought to produce LPS that activates TLRs 2 and $4^{16-18}$.

\section{Conclusion}

The zymography is a reproducible and reliable method to detect gelatinase activity at least of MMP-2 in primary cultures of human periodontal ligament fibroblasts with potential clinical applications.

\section{References}

1. Lisboa RA, Lisboa FA, Santos GC, Andrade MVM, Cunha-Melo JR. Matrix metalloproteinase 2 activity decreases in human periodontal ligament fibroblast cultures submitted to simulated orthodontic force. In Vitro Cell Dev Biol Anim. 2009;45:614-21.

2. Yao PM, Buhler JM, d'Ortho MP, Lebargy F, Delclaux C, Harf A, Lafuma C. Expression of matrix metalloproteinase gelatinase A and B by cultured epithelial cells from human bronchial explants. J Biol Chem. 1996;271:15580-9.

3. Van den Steen PE, Dubois B, Nelissen I, Rudd PM, Dwek RA, Opdenakker G. Biochemistry and molecular biology of gelatinase B or matrix metalloproteinase-9 (MMP-9). Crit Rev Biochem Mol Biol. 2002;37:375-536.

4. Quesada AR, Barbacid MM, Mira E, Fernández-Resa P, Márquez G, Aracil M. Evaluation of fluorometric and zymographic methods as activity assays for stromelysins and gelatinases. Clin Exp Metastasis. 1997;15:26-32.

5. Gogly B, Groult N, Hornebeck W, Godeau G, Pellat B. Collagen Zymography as a sensitive and specific technique for determination of subpicogram levels of interstitial collagenase. Anal Biochem. 1998;255:211-6

6. Makowski GS, Ramsby M. Calibrating gelatin zymograms with human gelatinase standards. Anal Biochem. 1996;236:353-6.

7. Leber TM, Balkwill FR. Zymography: a single-step staining method for quantitation of proteolytic activity on substrate gels. Anal Biochem. 1997;249:24-8.

8. Kleiner DE, Stetler-Stevenson G. Quantitative zymography: detection of pictogram quantities of gelatinases. Anal Biochem. 1994;218:325-9

9. Mahanonda R, Pichyangkul S. Toll-like receptors and their role in periodontal health and disease. Periodontol 2000. 2007;43:41-55.

10. Wong Y, Setbu C, Louafi F, Hossain P. Lipopolysaccharide regulation of toll-like receptor-4 and matrix metalloproteinase-9 in human primary corneal fibroblasts. Invest Ophthalmol Vis Sci. 2011;52:2796-803.

11. Redlich M, Roos H, Reichenberg E, Zaks B, Grosskop A, Kana IB, Pitaru S, Palmon A. The effect of centrifugal force on mRNA levels of collagenase, collagen type-I, tissue inhibitors of metalloproteinases and b-actin in cultured human periodontal ligament fibroblasts. J Periodontal Res. 2004;39:27-32.

12. Ra HJ; Parks WC. Control of matrix metalloproteinase catalytic activity. Matrix Biol. 2007; 6:587-96.

13. Fernandes-Resa P, Mira E, Quesada R. Enhanced detedtion of casein zymography of matrix metalloproteinases. Anall Biochem. 1995;224:434-5.

14. Ford PJ, Gamonal J, Seymour GJ. Immunological differences and similarities between chronic periodontitis and aggressive periodontitis. Periodontol 2000. 2010;53:111-23.

15. Sun Y, Shu R, Li C-L, Zhang M-Z. Gram-negative periodontal bacteria induce the activation of Toll-like receptors 2 and 4, and cytokine production in human in human periodontal ligament cells. J Periodontol. 2010;81:1488-96.

16. Ogawa T, Asai Y, Hashimoto M, Takeuchi O, Kurita T, Yoshikai Y, 
Miyake K, Akira S. Cell activation by Porphyromonas gingivalis lipid A molecule through toll-like receptor 4 and myeloid differentiation factor 88-dependent signaling pathway. Int Immunol. 2002;14:1325-32.

17. Darveau RP, Pham TTT, Lemley K, Reife RA, Bainbridge BW, Coats SR, Howald WN, Way SS, Hajjar AM. Porphyromonas gingivalis lipolysaccharide contains multiple lipid A species that functionally interact with both toll-like receptors 2 and 4 . Infect Immun. 2004;72:5041-51.

18. Wang YH, Jiang J, Zhu Q, AlAnezi AZ, Clark RB, Jiang X, Rowe DW, Nichols FC. Porphyromonas gingivalis lipids inhibit osteoblastic differentiation and function. Infect Immun 2010;78:3726-35.

\section{Acknowledgment}

Marcus Vinícius Andrade is supported by a NIH Grant 1 R01 TW 00612 (GRIP)

\section{Correspondence:}

Jose Renan Cunha-Melo

Departamento de Cirurgia, Faculdade de Medicina, UFMG

Avenida Professor Alfredo Balena, 190/ sala 295

30130-100 Belo Horizonte - MG Brasil

jrcmelo@medicina.ufmg.br

Received: October 23, 2012

Review: December 19, 2012

Accepted: January 22, 2013

Conflict of interest: none

Financial sources: FAPEMIG (Minas Gerais Research Foundation), CNPq (National Council of Technological and Scientific Development) and CAPES (Coordination of Improvement for Higher Academic Staff).

${ }^{1}$ Research performed at Professor Lineu Freire Maia Laboratory, Department of Surgery, School of Medicine, Minas Gerais Federal University (UFMG), Belo Horizonte-MG, Brazil. Part of PhD degree thesis, Pathology Postgraduate Program, Medical School, UFMG. Tutor: Jose Renan Cunha-Melo. 